Document downloaded from:

http://hdl.handle.net/10251/149553

This paper must be cited as:

Payri, R.; Gimeno, J.; Mata, C.; Viera-Sotillo, AA. (2017). Rate of injection measurements of a direct-acting piezoelectric injector for different operating temperatures. Energy Conversion and Management. 154:387-393. https://doi.org/10.1016/j.enconman.2017.11.029

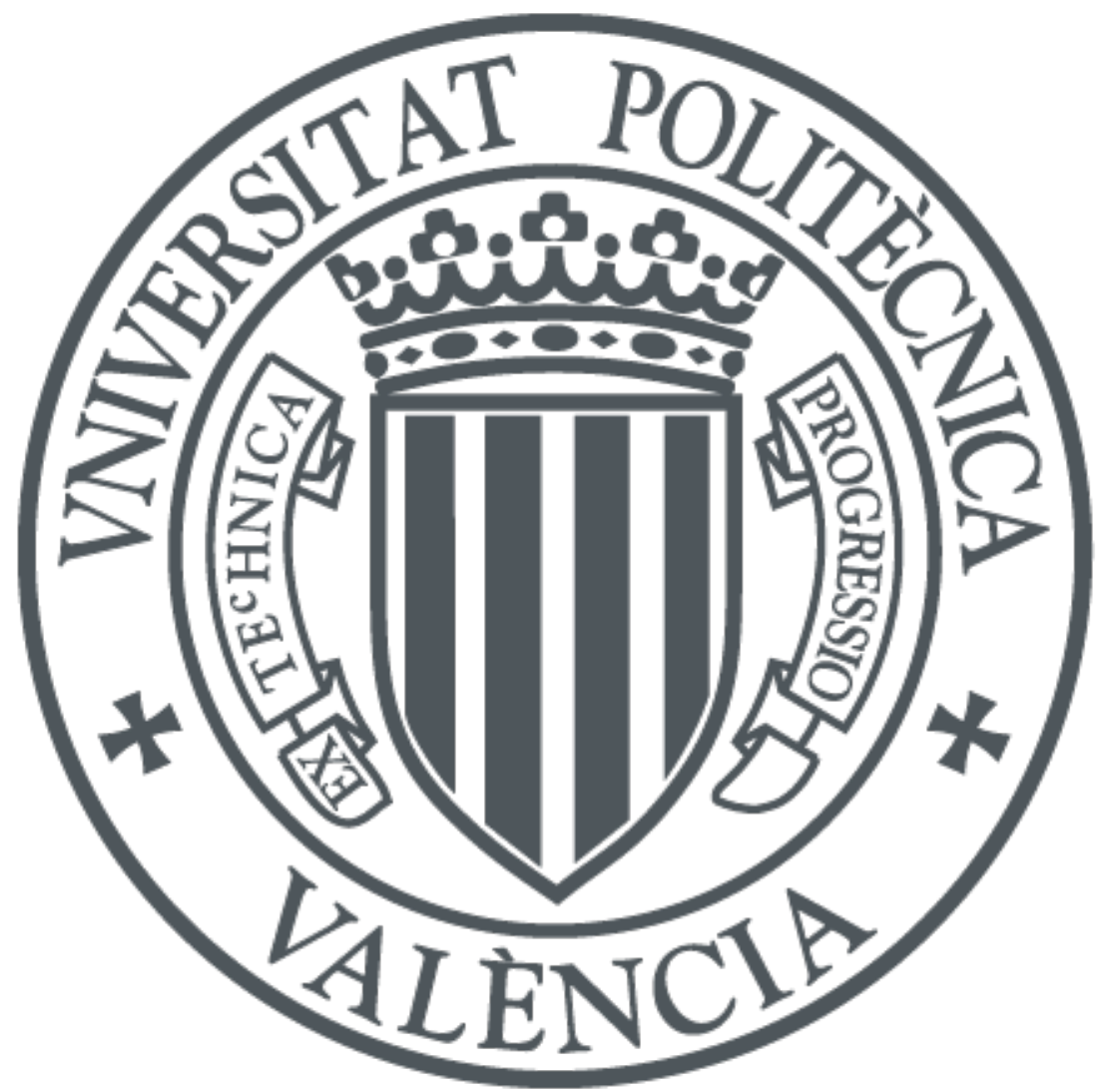

The final publication is available at

https://doi.org/10.1016/j.enconman.2017.11.029

Copyright Elsevier

Additional Information 
Raul Payri, Jaime Gimeno, Carmen Mata, Alberto Viera; Rate of injection measurements of a direct-acting piezoelectric injector for different operating temperatures. Energy Conversion and Management, 2017, 154, 387-393.

\title{
Rate of injection measurements of a direct-acting piezoelectric injector for different operating temperatures
}

\author{
Raul Payria ${ }^{\mathrm{a}, *}$, Jaime Gimeno ${ }^{\mathrm{a}}$, Carmen Mata ${ }^{\mathrm{b}}$, Alberto Viera $^{\mathrm{a}}$ \\ ${ }^{a}$ CMT - Motores Térmicos, Universitat Politècnica de València, Edificio 6D, 46022, Valencia, Spain. \\ ${ }^{b}$ Departamento de Mecánica Aplicada e Ingeniería de Proyectos, Universidad de Castilla La Mancha, \\ 13400, Almadén, Spain.
}

\begin{abstract}
As the regulations for pollutant emissions in diesel engines are increasingly restrictive, the introduction of the piezoelectric direct-acting injectors seeks to improve the overall efficiency of the injection system, and consequently reduce combustion contaminants. In such systems, the needle lift is governed by the charge, or voltage, applied to the piezo stack, allowing for a more precise control over the fuel injection process. Although it is known that the performance of the piezoelectric crystals depends on its temperature of operation, the effect this has on the rate of injection is still unclear. In this research, a particular setup was used to measure the rate of injection of a direct-acting injector for different operating temperatures. It was mounted into an injection discharge rate curve indicator with a particular holder that has a cooling sleeve connected to a circuit running ethylene glycol, which is driven by a thermoregulator unit. A parametric sweep of different piezo stack control voltages for three rail pressures and operating temperatures was carried out. On the results, when needle lift does not influence internal flow development, the rate of injection was controlled by the injection pressure, with minimal impact from the working temperature, resembling results from conventional hydraulic injectors. At partial needle lift, two operating regions were observed, delimited by a particular voltage level. Above it, the needle throttling was able to control mass fuel flow accurately. But below it, the stabilized rate of injection values decreased drastically. The rate of this decline was dependent only on the injection pressure. The threshold level, named critical voltage, increased linearly with increasing injection pressure and working temperature. Also, to maintain a constant fuel mass flow for decreasing operating temperature, the voltage level of the control signal had to be reduced. These results highlight the importance of monitoring and controlling the operating conditions of the direct-acting injectors, as their performance and efficiency are both influenced by the working temperature of the piezo stack.
\end{abstract}

Keywords: Diesel injection, direct-acting, rate of injection, operating temperature.

\footnotetext{
${ }^{*}$ Corresponding author. E-mail address: rpayri@mot.upv.es
} 
Raul Payri, Jaime Gimeno, Carmen Mata, Alberto Viera; Rate of injection measurements of a direct-acting piezoelectric injector for different operating temperatures. Energy Conversion and Management, 2017, 154, 387-393.

\begin{tabular}{llll}
\multicolumn{2}{l}{ Nomenclature } & & \\
$\Delta P$ & difference between injection and back & Top & operating temperature \\
& pressure & BP & back pressure \\
$\dot{m}_{\text {exp }}$ & stabilized rate of injection (mass flow) & ECN & Engine Combustion Network \\
$\rho_{f}$ & density of the fuel & IDRCI & injection discharge rate curve indica- \\
$A_{o}$ & outlet area of a nozzle & & tor \\
$C_{d}$ & discharge coefficient & ROI & rate of injection \\
$N_{o}$ & number of orifices & SOE & start of energizing \\
$P_{i n j}$ & injection pressure & &
\end{tabular}

\section{Introduction}

It is known that the standards regarding pollutant emissions generated by diesel engines are increasingly restrictive. Different solutions have been proposed to fulfill the limits established in the regulations, which includes the improvement of diesel injection systems [1, 2].

5 With the evolution from the conventional solenoid actuators into the hydraulic piezoelectric injectors, a more precise control over the fuel injection process was achieved, reducing combustion noise, fuel consumption and, consequently, pollutant emissions [3]. Furthermore, these injectors can produce short injection delays, due to a fast opening time of the needle, enabling them to perform multiple closely coupled pulses [1, 2].

The use of piezoelectric actuators in fuel injectors is still a science in development and presents some disadvantages. Furukawa et al. [4] and Fukada [5] established a direct link between temperature and changes of the charge constant and permittivity of the piezoelectric material, affecting its performance. Mitrovic et al. [6] concluded that operating (or working) temperature significantly influence the positioning accuracy and electric-field magnitude required to drive the piezoelectric actuators. Moreover, the actuators generate heat when operating both at high frequency and high electric field, and such situations could produce degradation of the piezoelectric stack [3, 6].

In the direct-acting injectors, the absence of hydraulic circuits, and thus the direct drive of the needle, provides greater accelerations in its opening phase [7]. In these injectors, it is possible to control the rate of injection (ROI) and momentum flux by only modifying the voltage signal, because of flow throttling due to partial needle lift [8 10]. Additionally, the control signal applied to the piezoelectric actuator further influences the spray penetration, both in the liquid and vapor phase [11-13. Consequently, as more parameters can be controlled, the possibilities for diesel combustion optimization are greater [14 16].

The direct-acting mechanism is the link between the actuator and the needle that amplifies the displacement of the piezo stack. Ferrari and Mittica [17] used a detailed mathematical model to study the influence of how the injection pressure affected this mechanism (a swinging rocker arm) and concluded that deformations caused by the high forces on the system have a significant impact in the lifting of the needle, especially at high pressures. 
Raul Payri, Jaime Gimeno, Carmen Mata, Alberto Viera; Rate of injection measurements of a direct-acting piezoelectric injector for different operating temperatures. Energy Conversion and Management, 2017, 154, 387-393.

Subsequently, Viera et al. 99 reported these deformations reduced the operational window of the injector. The authors suggested a minimum voltage limit, dependent on the injection pressure, where above this limit the injector performance was stable and controllable, and below it, it performed inconsistently. Payri et al. [13] observed spray penetrations in liquid and vapor phases for different control voltages (95 to $150 \mathrm{~V}$ ) and injection pressures (50 and $150 \mathrm{MPa}$ ), linking the results with needle lift and ROI measured by Viera et al. [9]. However, as measurements were carried out in different facilities, spray penetration, and hydraulic measurements did not correlate as expected near this critical voltage value, justified by the different injector operating temperatures between test vessels. Altieri and Tonoli [18] performed experimental measurements of the piezo stack displacement for different working temperatures $\left(20\right.$ to $85^{\circ} \mathrm{C}$ ) and charge (voltage) levels (70 to $150 \mathrm{~V}$ ), and reported that increasing the working temperature resulted in longer displacement for a constant voltage level, with almost a linear ratio. Similar results were obtained by Li et al. [19], who performed a quasi-static thermo-electro-mechanical experimental analysis of a piezoelectric actuator, and found that the electric-field-induced stroke increased steadily with temperature.

Even though it is known that the operating temperature of the piezo stack affects its behavior, it is still necessary to identify how this effect is translated into the hydraulic performance of the direct-acting injector. Furthermore, experimental results could prove useful for validation and improvement of mathematical models. Accordingly, this paper studies the influence of different operating temperatures $\left(30,60\right.$ and $\left.90{ }^{\circ} \mathrm{C}\right)$ in the ROI, for sweeps of the control voltage at three injection pressure levels. For the ROI measurements, a conventional Bosch long tube method tester has been used [20]. A cooling jacket, fitted with a thermocouple, was designed to monitor and control the temperature of the injector body.

This paper is divided into four sections. Following this introduction, the experimental facility and measurement methodology are detailed. Then, results and discussions are presented, organized by the effect of the different boundary conditions studied. In the last section, the conclusions are drawn.

\section{Materials and Methods}

This section presents the experimental equipment and data processing methodology.

\subsection{Fuel delivery system}

The injection system is comprised of commercially available components. The highpressure unit consists of a Bosch CP3 pump, powered by an electric motor, and a commonrail equipped with a pressure regulator, which is driven by a proportional-integral-derivative controller. The whole subsystem is assembled on a moving cart, that encloses all components. The pressurized fuel is delivered to a second common-rail (volume $=22 \mathrm{~cm}^{3}$, length $=$ $28 \mathrm{~cm}$ ), and fed to the injector through a high-pressure rigid line (inside/outside diameter $=2.4 / 6 \mathrm{~mm}$, length $24 \mathrm{~cm}$ ). The configuration was selected to replicate the setup used by previous authors 9, 13], and complies with Engine Combustion Network (ECN) standards [21. 
Raul Payri, Jaime Gimeno, Carmen Mata, Alberto Viera; Rate of injection measurements of a direct-acting piezoelectric injector for different operating temperatures. Energy Conversion and Management, 2017, 154, 387-393.

The injector, also utilized in the research of other authors [9, 13, is equipped with a piezoelectric actuator directly connected to the needle through a mechanical link. This direct-acting coupling is similar to the one presented by Ferrari and Mittica [17], and consists of a swinging rocker arm that amplifies the displacement of the piezo stack when a control signal is applied. The injector is equipped with a 7-hole nozzle, with an averaged outlet diameter of $110.6 \mu \mathrm{m}$. Following the guidelines of previous authors [9, 13, a long energizing time of $3.2 \mathrm{~ms}$ is used, to fully decoupled transient and steady parts of the injection event.

\subsection{Rate of injection meter}

Measurements of the ROI were carried out with an Injection Discharge Rate Curve Indicator (IDRCI), based on the Bosch long tube method. In these systems, fuel is injected into a calibrated and pressurized fuel-filled measuring tube, creating a pressure increase that is proportional to the mass introduced. A high-speed transducer captures the rate of pressure increase within the test cell, that is then translated to the ROI. More information regarding the experimental apparatus is available in the work of other authors 22 24].

\subsection{Injector temperature control}

A new injector holder was designed and manufactured, that enabled to monitor and control the operating temperature of the piezo stack. A schematic diagram of the ROI setup is presented in Figure 1. The adapter has a cooling sleeve that surrounds the injector body from near the nozzle tip up to the mounting clamp. The sleeve is connected to a thermoregulator unit that drives a circuit of ethylene glycol. As a reference for the working temperature, a $1 \mathrm{~mm}$ thermocouple, $T$ in the figure, was inserted in the upper half of the cooling sleeve, in contact with the body of the injector. As a consequence, the operating

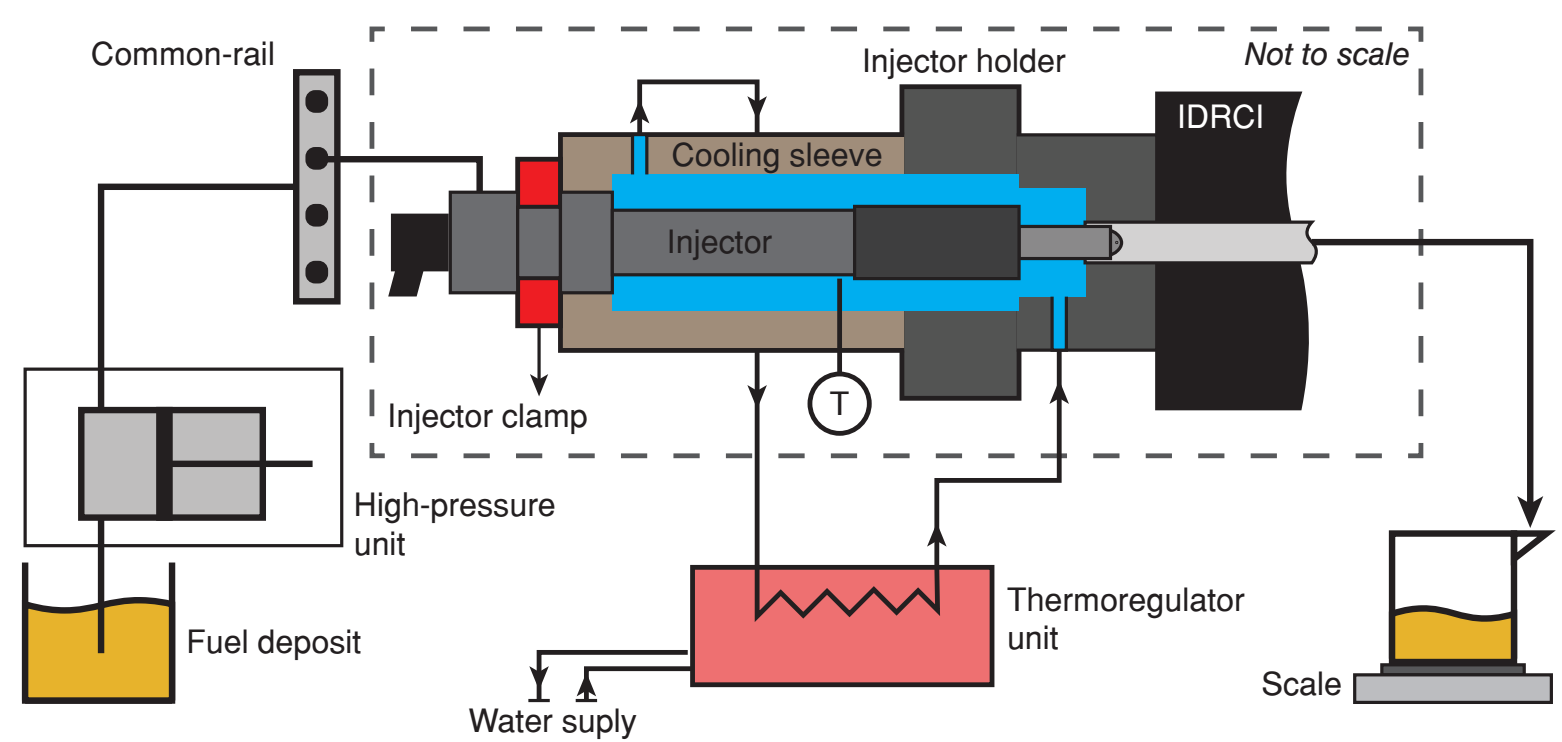

Figure 1: Schematic diagram of the experimental setup with the temperature control circuit. The thermocouple $\mathrm{T}$ was used as reference for the piezo stack operating temperature. 
Raul Payri, Jaime Gimeno, Carmen Mata, Alberto Viera; Rate of injection measurements of a direct-acting piezoelectric injector for different operating temperatures. Energy Conversion and Management, 2017, 154, 387-393.

temperature of the piezo stack is not directly measured and controlled. Still, enough time was provided to the system to reach thermal equilibrium, following a similar procedure as Altieri and Tonoli [18, and at least assuring that different operating conditions regarding

\subsection{Raw data post-processing}

A high-speed acquisition system was used to capture the ROI signal. 50 cycles (or shots) are recorded per test condition. The raw data is averaged and then corrected to account for the signal cumulative phenomenon [23]. The final curve is integrated to obtain the total mass per injection. Then, this is compared to the mass increase of a single shot, which is measured by a high precision scale located downstream of the IDRCI (see Figure 1). As both quantities should be equal, due to mass conservation, the ROI curve is corrected to target the mass measured by the scale. Figure 2 presents an example of the raw data as different colors, and in black the resultant curve after all corrections.

The stabilized rate-of-injection $\left(\dot{m}_{\text {exp }}\right)$, or mass flow, is calculated as an average value within a time window 25], presented as dashed lines in Figure 2, where the time is referenced to the start of energizing (SOE). The interval is selected near the end-of-injection region, where the oscillations of the signal are minimal (see Figure 2), and is fixed for all test conditions.

The discharge coefficient $\left(C_{d}\right)$ indicates the general performance of the injector [26], and is calculated as the ratio between the experimental $\left(\dot{m}_{\text {exp }}\right)$ and theoretical $\left(\dot{m}_{t h}\right)$ stabilized ROI (Equation 1).

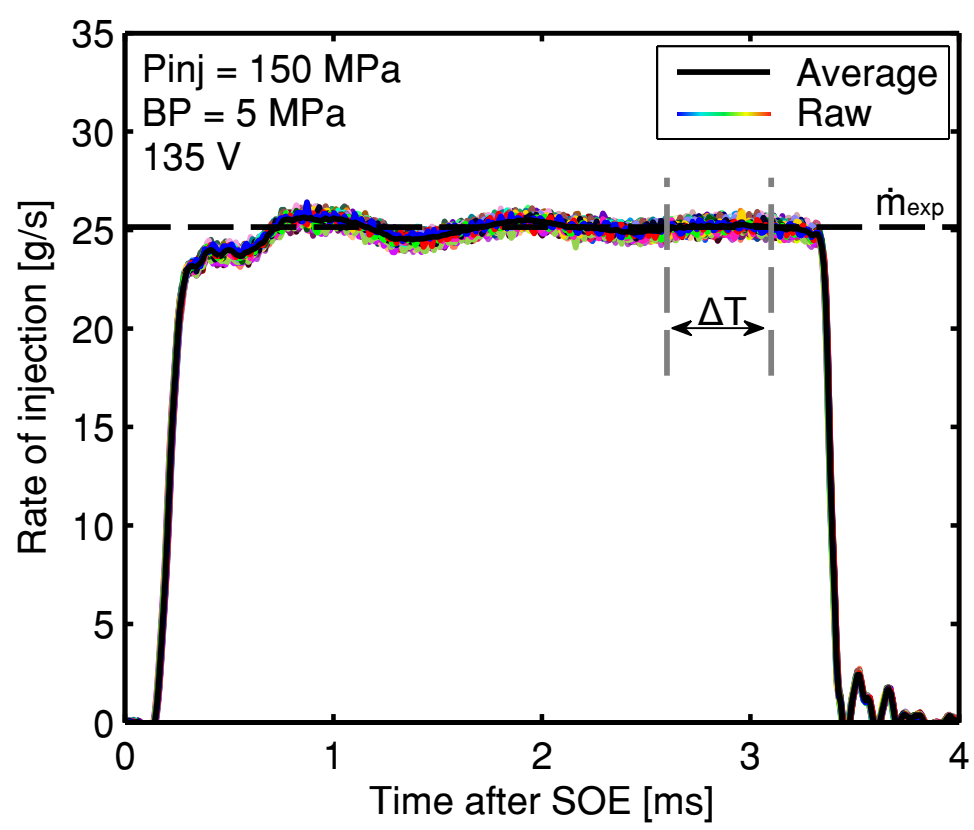

Figure 2: Example of the raw (colors) and averaged (black) data. The stabilized rate of injection $\dot{m}_{\text {exp }}$ is calculated as the mean value within the time window $\Delta \mathrm{T}$. 
Raul Payri, Jaime Gimeno, Carmen Mata, Alberto Viera; Rate of injection measurements of a direct-acting piezoelectric injector for different operating temperatures. Energy Conversion and Management, 2017, 154, 387-393.

$$
C_{d}=\frac{\dot{m}_{e x p}}{\dot{m}_{t h}}=\frac{\dot{m}_{\text {exp }}}{N_{o} A_{o} \sqrt{2 \rho_{f} \Delta P}}
$$

Where $N_{o}$ is the number of orifices, $A_{o}$ is the outlet area of a nozzle, calculated with the average diameter, $\rho_{f}$ is the density of the fuel, and $\Delta P$ is the difference between injection and discharge pressure (back pressure). The density was calculated using the correlation presented by Payri et al. [27] for commercial diesel fuel, with the temperature measured by a thermocouple located in the discharge section.

\subsection{Test matrix}

Experimental conditions were selected with the work of previous authors as reference [9, 13], and are presented in Table 1. Different piezo stack voltage levels for three injection pressures and operating temperatures were analyzed.

Table 1: Test conditions.

\begin{tabular}{lcc}
\hline Parameter & Value & Units \\
\hline Fuel & Diesel $^{*}$ & - \\
Energizing time & 3.2 & $\mathrm{~ms}$ \\
Injection pressure $\left(P_{\text {inj }}\right)$ & $50-100-150$ & $\mathrm{MPa}$ \\
Voltage & $67-150^{* *}$ & $\mathrm{~V}$ \\
Operating Temperature $(T o p)$ & $30-60-90$ & ${ }^{\circ} \mathrm{C}$ \\
Back pressure $(B P)$ & 5 & $\mathrm{MPa}$ \\
Cycles measured & 50 & - \\
\hline
\end{tabular}

${ }^{*}$ Properties found as reference fuel [27].

** Voltage levels depended on the injection pressure.

\section{Results and discussion}

This section presents the results of the averaged ROI signals, grouped by parameter variation.

\subsection{Injection pressure}

The effect of injection pressure on the ROI is known. But still, understanding how it affects the performance of a direct-acting injector, at constant levels of operating temperature and charge, is interesting for further analysis. Figure 3 presents ROI signals for different injection pressure and two voltage levels (135 V on the left and $100 \mathrm{~V}$ on the right), at a constant working temperature of $90^{\circ} \mathrm{C}$.

The left subplot depicts a relatively high voltage level in the operating window of the three injection pressures, where needle lift does not affect internal flow development 9 . As a consequence, mass flow directly depends on the pressure difference, or the expression $\sqrt{2 \Delta P}$ in Equation 1, and resembling results from conventional hydraulic injectors [24, 28, 30]. 
Raul Payri, Jaime Gimeno, Carmen Mata, Alberto Viera; Rate of injection measurements of a direct-acting piezoelectric injector for different operating temperatures. Energy Conversion and Management, 2017, 154, 387-393.

On the contrary, the right plot shows a relatively low voltage, where the needle generates a pressure drop in the seat and affects flow conditions at the outlet of the nozzle [8]. Consequently, for a constant piezo stack voltage, the increasing forces induced for higher injection pressure levels over the direct-acting mechanism, results in lower needle lift, and thus, the rate of injection [9, 13, 31]. However, the tipping point where curves do not follow the dependence on the pressure difference, at partial needle lift, changes for each injection pressure and is discussed in the following sections.
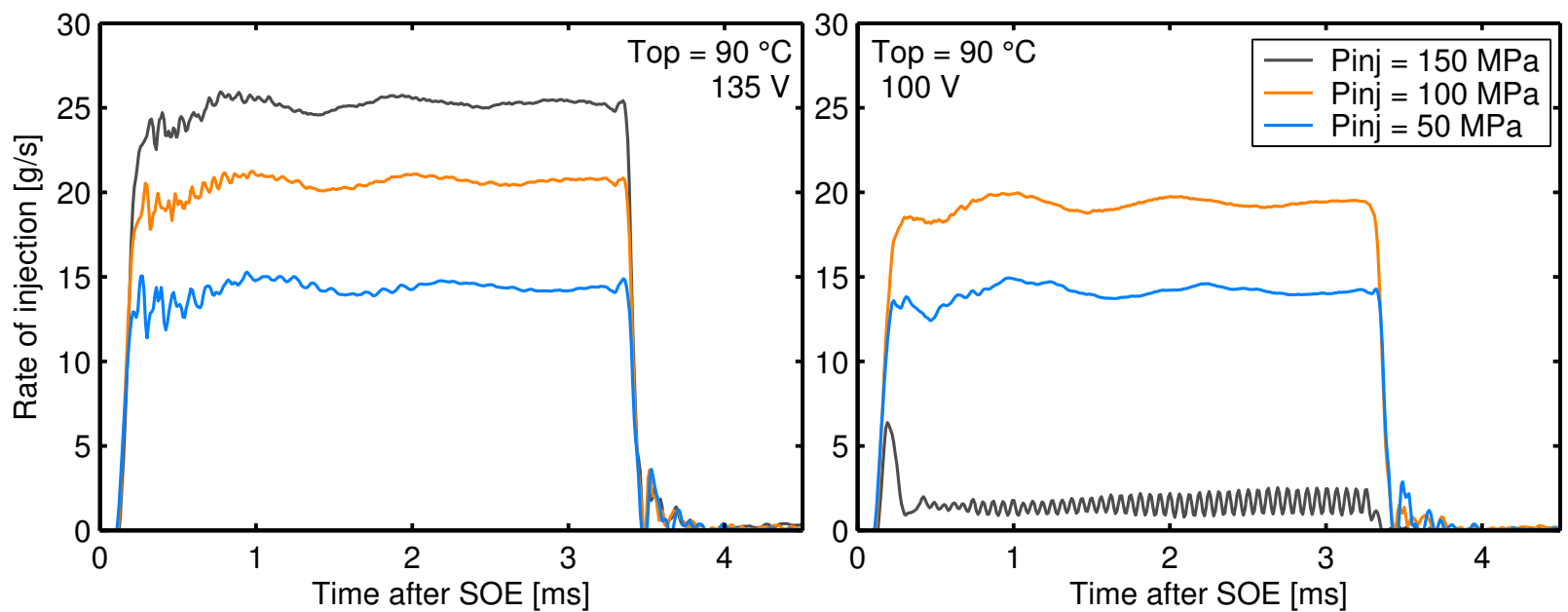

Figure 3: Effect of the injection pressure on the rate of injection, at $135 \mathrm{~V}$ (left) and 100V (right), and a constant operating temperature. The legend is common for both plots.

\subsection{Piezo stack voltage}

Figure 4 depicts the results of ROI for different voltage levels, two injection pressures, $50 \mathrm{MPa}$ (left) and $150 \mathrm{MPa}$ (right), and a constant operating temperature of $90^{\circ} \mathrm{C}$.

At low injection pressure, the ROI signal starts being influenced by the needle for values less than $110 \mathrm{~V}$, with ROI decreasing steadily while reducing the charge in decrements of $5 \mathrm{~V}$ up to $67 \mathrm{~V}$. On the contrary, at $150 \mathrm{MPa}$, mass flow is already controlled by lift for values lower than $120 \mathrm{~V}$, and with a minimum voltage of only $100 \mathrm{~V}$. Besides, when decreasing the charge applied to the piezo stack lower than $110 \mathrm{~V}$, the ROI signal was unstable, and a slight change in the piezo stack voltage produced a drastic shift in the outcome. Therefore, the operating window, where the activation signal smoothly controls the ROI, is reduced with increasing injection pressure.

This difference observed in Figure 4 is because more energy is necessary to overcome the deflections and deformations caused by the high injection pressure levels over the directacting coupling [9, 13, 17, 31, as also observed in Figure 3. Thus, and in contrast to results at $50 \mathrm{MPa}$, the pivoting point widens, and no smooth transition between the ROI results is observed. Consequently, three operational regions with decreasing piezo stack voltage can be depicted. Firstly, when the force generated by the piezoelectric crystal overcomes the widened pivoting point, and ROI is controlled either by the pressure difference and flow throttling by the needle if it is the case. Secondly, when for a range of voltages applied to 
Raul Payri, Jaime Gimeno, Carmen Mata, Alberto Viera; Rate of injection measurements of a direct-acting piezoelectric injector for different operating temperatures. Energy Conversion and Management, 2017, 154, 387-393.

the piezo stack, an unstable cycle-to-cycle behavior over the widened pivoting point creates significant ROI fluctuations [9]. And thirdly, when a ROI signal is observed at low voltage value, that is probably limited by the elastic deformations of the rocker, as forces over the direct-acting coupling increase as the needle lift starts.
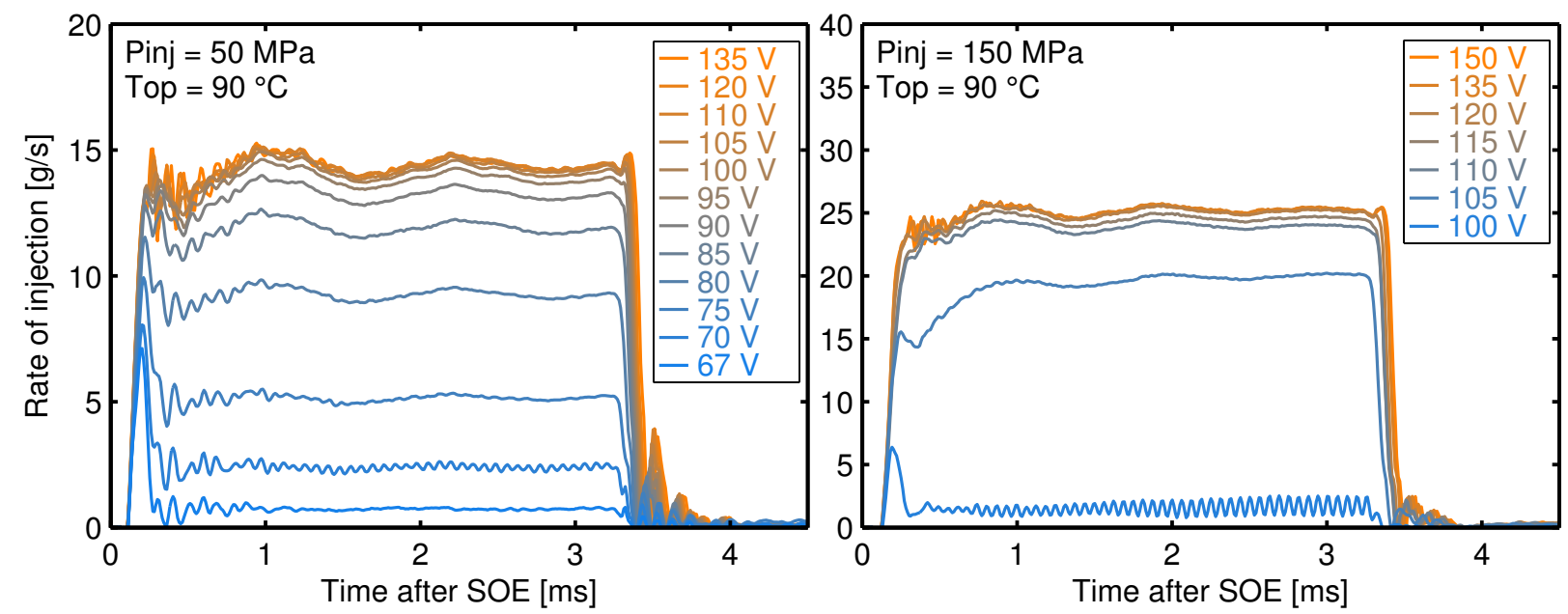

Figure 4: Effect of the piezo stack voltage on the rate of injection, for rail pressures of $50 \mathrm{MPa}$ (left) and $150 \mathrm{MPa}$ (right), and a constant operating temperature.

\subsection{Operating temperature}

Figure 5 presents the results of ROI for different operating temperatures, at rail pressures of $50 \mathrm{MPa}$ (in the left column, subplots $a-c$ ) and $150 \mathrm{MPa}$ (in the right column, subplots $d-f)$, and three voltage levels.

Once again, for high voltage level (subplots $a$ and $d$ ), as needle position does not influence internal flow development, the ROI is governed by the pressure difference along the nozzle. The minor differences in mass flow can be attributed to small changes in fuel density due to the working temperature (Equation 1). For decreasing voltage levels, and the needle lift starts contributing to flow control, a strong influence from the operating temperature is observed.

Fukada [5] established that a simple linear relation exists between the characteristical parameters of a piezoelectric crystal and temperature. Altieri and Tonoli [18] confirmed this connection with experimental results, proving that the axial displacement of the piezo stack increased, in general terms, linearly with temperature. Consequently, trends observed in ROI signals, influenced by needle position, in Figure 5 are in agreement with trends expected from the literature. For a constant voltage level, as the working temperature increases, the displacement of the piezo stack increases as well, resulting in a higher needle lift, and thus, a higher ROI. In addition, the differences observed between injection pressure depict a similar trend to what was seen in Figure 4. At high injection pressure, a drastic decrease in the ROI signal is noted in subplot $(e)$ at $120 \mathrm{~V}-30{ }^{\circ} \mathrm{C}$, and again in subplot $(f)$ at $110 \mathrm{~V}-60{ }^{\circ} \mathrm{C}$, proving that the operating temperature is a determinant factor in the performance of the injector. 
Raul Payri, Jaime Gimeno, Carmen Mata, Alberto Viera; Rate of injection measurements of a direct-acting piezoelectric injector for different operating temperatures. Energy Conversion and Management, 2017, 154, 387-393.
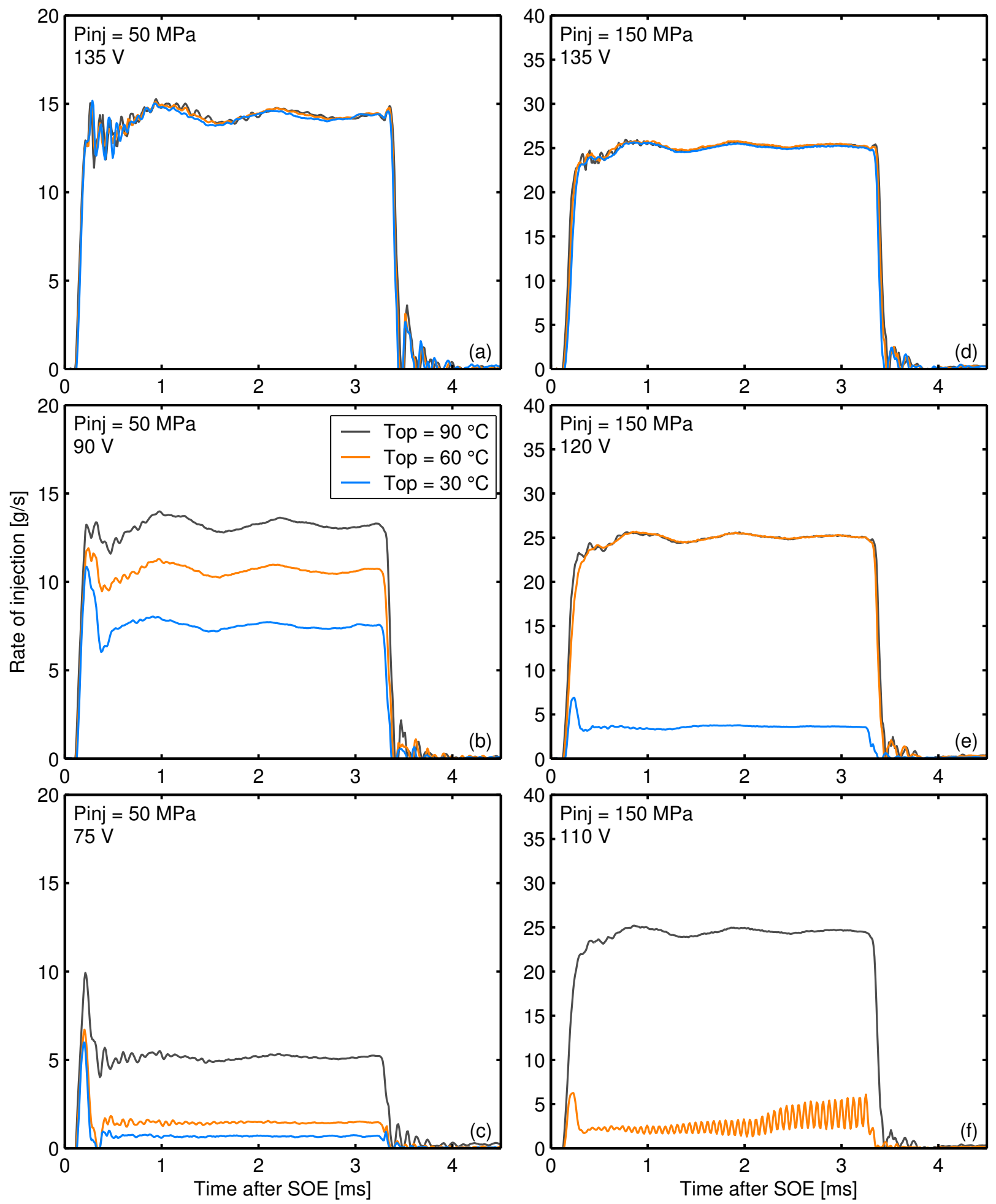

Figure 5: Effect of the piezo stack operating temperature on the rate of injection, at three different voltage levels and a constant injection pressure. The legend is common for all the plots. 
Raul Payri, Jaime Gimeno, Carmen Mata, Alberto Viera; Rate of injection measurements of a direct-acting piezoelectric injector for different operating temperatures. Energy Conversion and Management, 2017, 154, 387-393.

\subsection{Mass flow and discharge coefficient}

By calculating the mass flow (or stabilized ROI), it is possible to analyze the influence of all boundary conditions in one graph, as presented in Figure 6. a, where mass flow is depicted for different voltage levels. Operating temperature and injection pressure conditions are represented with different colors and symbols, respectively.
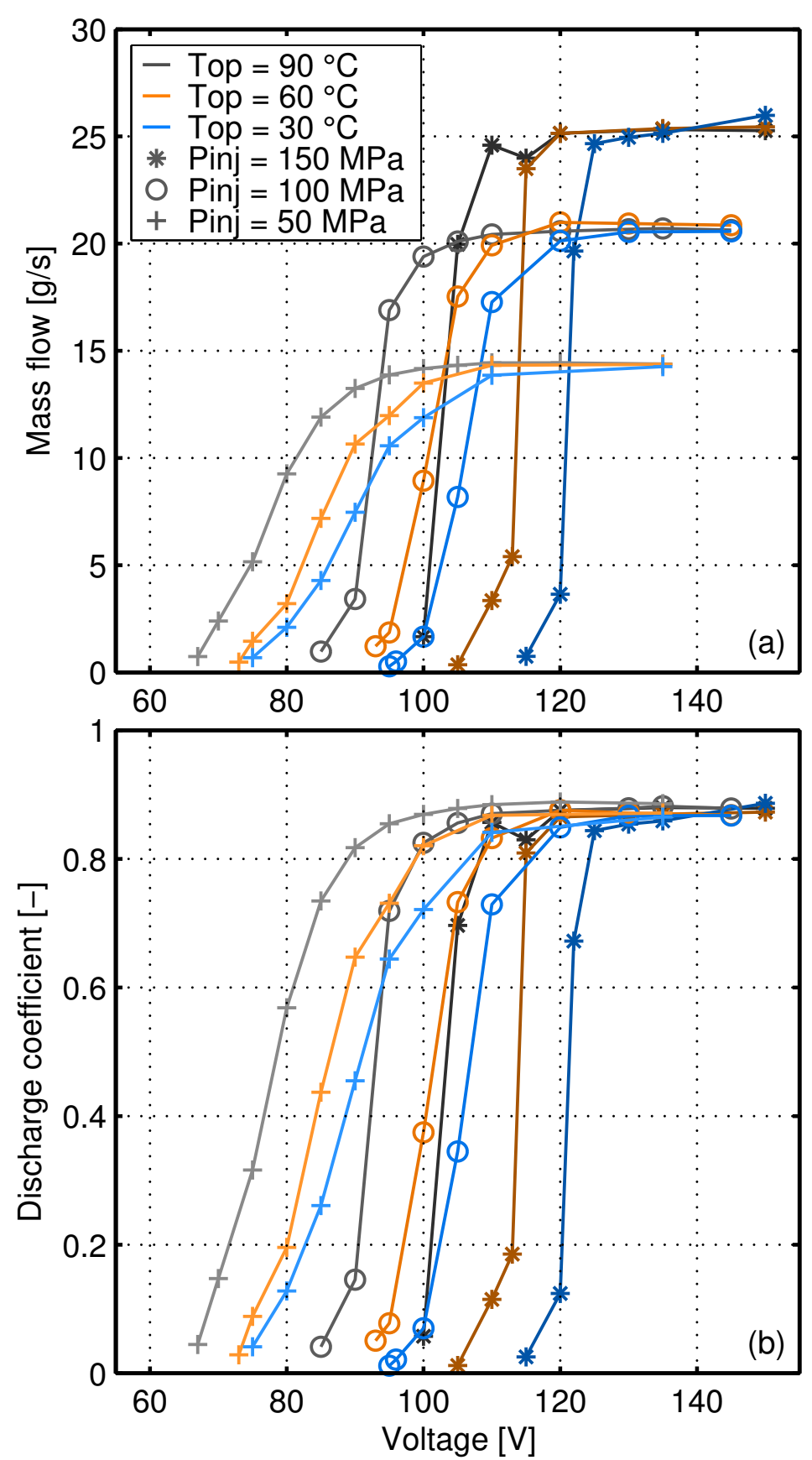

Figure 6: Mass flow (a) and discharge coefficient (b) for all conditions tested. The legend is common for both plots. 
Raul Payri, Jaime Gimeno, Carmen Mata, Alberto Viera; Rate of injection measurements of a direct-acting piezoelectric injector for different operating temperatures. Energy Conversion and Management, 2017, 154, 387-393.

As all tested conditions are summarized in Figure 6. Trends discussed in the previous are also depicted here, as, in general terms, stabilized ROI increases with increasing injection pressure, voltage, and operating temperature. Moreover, in Figure 6.a, for decreasing voltage, a sharp decline in the mass flow after a certain charge value is visible. This trend becomes more evident and severe at a high injection pressure, thus confirming a reduction in the operating range of the injector. Also, for a fixed rail pressure, as operating temperature increases, the voltage needed to maintain a constant mass flow value decreases. This trend would explain the discontinuity observed in the result presented by Viera et al. [9] and Payri et al. [13], where for certain conditions at a high injection pressure, liquid and vapor phase penetration did not correlate well with ROI and needle lift measurements. As experiments were carried out in different experimental facilities, a small difference in the operating temperature for conditions near the critical voltage level could have affected the performance of the injector, resulting in different mass flow values.

In Figure 6.b, as the piezo stack voltage increases, all test conditions values converge to the nominal discharge coefficient for the injector, that is, without an influence of the needle in the internal flow development. The effect of needle throttling on the internal flow is visible with decreasing voltage, with the discharge coefficients reaching values near zero.

\subsection{Critical voltage}

As mentioned in previous sections, the critical voltage is a level where, above it, fuel flow can be smoothly controlled with the charge sent to the injector. As observed in Figure 6. a, below this level flow mass collapses with a rate that depends on the injection pressure. Figure 7 presents the critical voltage for all test conditions, calculated as the first charge level with a rate of decrease higher than $0.6 \mathrm{~g} / \mathrm{s} . \mathrm{V}$ in Figure 6 . a, after smoothing the curves.

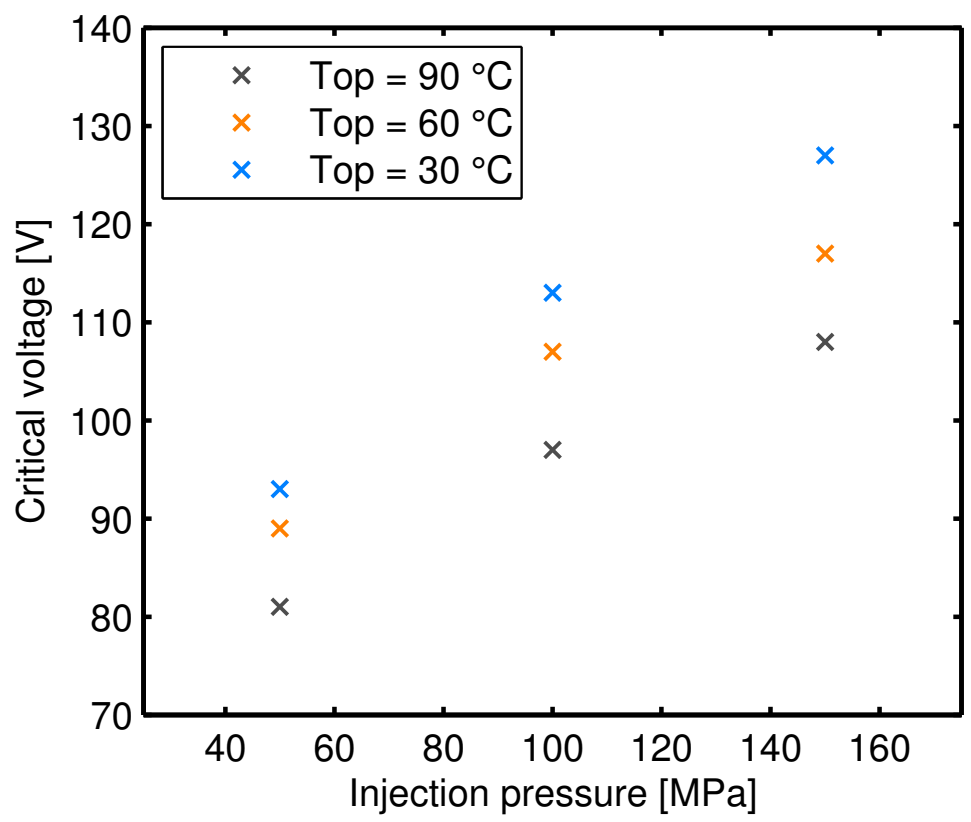

Figure 7: Critical voltage for all conditions tested. 
Raul Payri, Jaime Gimeno, Carmen Mata, Alberto Viera; Rate of injection measurements of a direct-acting piezoelectric injector for different operating temperatures. Energy Conversion and Management, 2017, 154, 387-393.

The threshold level was selected accounting for the ROI of the lowest injection pressure level, which is considerably smaller compared to the other two. From the figure, the critical voltage increases linearly with increasing injection pressure and working temperature. Furthermore, when the injector operates at low temperature $\left(30^{\circ} \mathrm{C}\right)$ the critical voltage is much higher, reducing its operating range.

\section{Conclusions}

Experimental measurements of the rate of injection were carried out for a diesel piezoelectric direct-acting injector, to study the influence of the operating temperature in its performance. A new injector holder was manufactured, with a cooling sleeve connected to a thermoregulator that drives a circuit containing ethylene glycol. A wide span of piezo stack voltage levels was analyzed for three injection pressures and temperatures. Commercial diesel fuel was used.

When the needle does not influence internal flow development, the ROI is governed by the difference in pressure between injection and discharge, as in conventional hydraulic diesel injectors. Additionally, for these conditions, a minimal effect from the operating temperature in the stabilized ROI was observed, related to the changes in fuel density in the discharge region.

For a constant voltage level, increasing injection pressure could lead to a decrease in the stabilized ROI. The force induced by higher pressure levels over the direct-acting coupling increases, thus for an energy input to the piezo stack, the needle lift achieved is lower, thus throttling effects can occur. In addition, the pivoting point in the direct-acting coupling widens. As a consequence, the operational window for controlling mass flow with needle throttling is reduced. Three different operational regimes were observed:

- When, above a critical voltage level, the force generated by the piezo stack overcomes this widened pivot, ROI is controlled either by the pressure difference and flow throttling by the needle if it is the case.

- When, below a critical voltage level, an unstable cycle-to-cycle behavior over the widened pivoting point creates significant ROI fluctuations.

- When, for low voltage values, a low ROI signal was observed, probably caused by elastic deformations in the direct-acting coupling.

The critical voltage was found to increase linearly with increasing injection pressure and the operating temperature.

Asides from the known influence of voltage, the piezo stack displacement also increases rather linearly with its temperature. Consequently, for constant conditions of injection pressure and voltage, the stabilized ROI increased with increasing operating temperature. Alternatively, to achieve a constant mass flow, the voltage applied to the piezo stack needs to be reduced with increasing temperature. 
Raul Payri, Jaime Gimeno, Carmen Mata, Alberto Viera; Rate of injection measurements of a direct-acting piezoelectric injector for different operating temperatures. Energy Conversion and Management, 2017, 154, 387-393. REFERENCES

Monitoring and controlling the operating conditions of piezoelectric direct-acting injectors is essential, as their performance and efficiency are both influenced by the working temperature of the piezo stack.

\section{Acknowledgments}

This research has been partially funded by FEDER and Spanish Ministerio de Economía y Competitividad through project TRA2015-67679-c2-1-R. Additionally, financial support to Dr. Carmen Mata was provided by "Ayudas para estancias en otras universidades y centros de investigación 2017" of Universidad de Castilla la Mancha. Likewise, Alberto Viera is supported through the FPI contract 2016-S2-1361 of "Programa de Apoyo para la Investigación y Desarrollo (PAID)" of Universitat Poltècnica de València.

The authors would like to thank Pablo Pérez Puyol for his collaboration on the experimental gathering of the data.

\section{References}

[1] H. K. Suh, S. W. Park, C. S. Lee, Effect of piezo-driven injection system on the macroscopic and microscopic atomization characteristics of diesel fuel spray, Fuel 86 (2007) 2833-2845. doi:10.1016/j . fuel.2007.03.015

[2] C. A. Satkoski, N. S. Ruikar, S. D. Biggs, G. M. Shaver, Piezoelectric fuel injection: Cycle-to-cycle control of tightly spaced injections, Control Engineering Practice 20 (2012) 1175-1182. doi $10.1016 /$ j.conengprac.2012.06.002.

[3] M. S. Senousy, R. K. N. D. Rajapakse, D. Mumford, M. S. Gadala, Self-heat generation in piezoelectric stack actuators used in fuel injectors, Smart Materials and Structures 18 (2009) 045008. doi 10.1088/ 0964-1726/18/4/045008.

[4] T. Furukawa, M. Date, E. Fukada, Y. Tajitsu, A. Chiba, Ferroelectric Behavior in the Copolymer of Vinylidenefluoride and Trifluoroethylene, Japanese Journal of Applied Physics 19 (1980) L109-L112. doi:10.1143/JJAP.19.L109.

[5] E. Fukada, History and Recent Progress in Piezoelectric Polymers, IEEE Transactions on Ultrasonics, Ferroelectrics and Frequency Control. 47 (2000) 1277-1290. doi $10.1109 / 58.883516$.

[6] M. Mitrovic, G. P. Carman, F. K. Straub, Response of piezoelectric stack actuators under combined electro-mechanical loading, International Journal of Solids and Structures 38 (2001) 4357-4374. doi:10. 1016/S0020-7683(00)00273-0.

[7] J. Lee, K. Min, Hydraulic Simulation and Experimental Analysis of Needle Response and Controlled Injection Rate Shape Characteristics in a Piezo-driven Diesel Injector, SAE Technical Paper 2006-011119 (2006). doi:10.4271/2006-01-1119.

[8] R. Payri, J. Gimeno, O. Venegas, A. H. Plazas-Torres, Experimental and Computational Study of the Influence of Partial Needle Lift on Nozzle Flowin Diesel Fuel Injectors, Atomization and Sprays 22 (2012) 687-714. doi:10.1615/AtomizSpr.2012005810.

[9] J. P. Viera, R. Payri, A. B. Swantek, D. J. Duke, N. Sovis, A. L. Kastengren, C. F. Powell, Linking instantaneous rate of injection to X-ray needle lift measurements for a direct-acting piezoelectric injector, Energy Conversion and Management 112 (2016) 350-358. doi:10.1016/j.enconman.2016.01.038

[10] F. J. Salvador, J. Martínez-López, M. Caballer, C. De Alfonso, Study of the influence of the needle lift on the internal flow and cavitation phenomenon in diesel injector nozzles by CFD using RANS methods, Energy Conversion and Management 66 (2013) 246-256. doi 10.1016/j.enconman.2012.10.011.

[11] R. Payri, J. Gimeno, M. Bardi, A. H. Plazas, Study liquid length penetration results obtained with a direct acting piezo electric injector, Applied Energy 106 (2013) 152-162. doi:10.1016/j.apenergy . 2013.01 .027 
Raul Payri, Jaime Gimeno, Carmen Mata, Alberto Viera; Rate of injection measurements of a direct-acting piezoelectric injector for different operating temperatures. Energy Conversion and Management, 2017, 154, 387-393. REFERENCES

[12] R. Payri, J. Gimeno, J. P. Viera, A. H. Plazas, Needle lift profile influence on the vapor phase penetration for a prototype diesel direct acting piezoelectric injector, Fuel 113 (2013) 257-265. doi:10.1016/j.fuel.2013.05.057.

[13] R. Payri, F. J. Salvador, J. Gimeno, A. Viera, in: H. Tschöke, R. Marohn (Eds.), 10. Tagung Diesel- und Benzindirekteinspritzung 2016, 1, Springer Vieweg, 2017, pp. 133-152. doi 10.1007/ 978-3-658-15327-4.

[14] K. Koyanagi, H. Öing, G. Renner, R. Maly, Optimizing Common Rail-Injection by Optical Diagnostics in a Transparent Production Type Diesel Engine, SAE Technical Paper 1999-01-3646 (1999). doi:10. 4271/1999-01-3646.

[15] S. Mendez, B. Thirouard, Using Multiple Injection Strategies in Diesel Combustion: Potential to Improve Emissions, Noise and Fuel Economy Trade-Off in Low CR Engines, SAE Technical Paper 2008-01-1329 1 (2008) 662-674. doi:10.4271/2008-01-1329.

[16] V. Macian, R. Payri, S. Ruiz, M. Bardi, A. H. Plazas, Experimental study of the relationship between injection rate shape and Diesel ignition using a novel piezo-actuated direct-acting injector, Applied Energy 118 (2014) 100-113. doi:10.1016/j .apenergy.2013.12.025.

[17] A. Ferrari, A. Mittica, FEM modeling of the piezoelectric driving system in the design of direct-acting diesel injectors, Applied Energy 99 (2012) 471-483. doi:10.1016/j.apenergy.2012.05.048

[18] L. Altieri, A. Tonoli, Piezoelectric Injectors for Automotive Applications: Modeling and Experimental Validation of Hysteretic Behavior and Temperature Effects, Journal of Dynamic Systems, Measurement, and Control 135 (2012) 11005. doi:10.1115/1.4006627.

[19] F. X. Li, R. K. N. D. Rajapakse, D. Mumford, M. Gadala, Quasi-static thermo-electro-mechanical behaviour of piezoelectric stack actuators, Smart Materials and Structures 17 (2008) 015049. doi:10. 1088/0964-1726/17/1/015049.

[20] W. Bosch, The Fuel Rate Indicator: A New Measuring Instrument for Display of the Characteristics of Individual Injection, SAE Technical Paper 660749 (1966). doi:10.4271/660749.

[21] ECN, Engine Combustion Network, Online, 2010. URL: www.sandia.gov/ecn/.

[22] R. Payri, J. M. García, F. J. Salvador, J. Gimeno, Using spray momentum flux measurements to understand the influence of diesel nozzle geometry on spray characteristics, Fuel 84 (2005) 551-561. doi:10.1016/j.fuel.2004.10.009.

[23] R. Payri, F. J. Salvador, J. Gimeno, G. Bracho, A new methodology for correcting the signal cumulative phenomenon on injection rate measurements, Experimental Techniques 32 (2008) 46-49. doi 10.1111/ j.1747-1567.2007.00188.x.

[24] F. J. Salvador, J. Gimeno, M. Carreres, M. Crialesi-Esposito, Fuel temperature influence on the performance of a last generation common-rail diesel ballistic injector. Part I: Experimental mass flow rate measurements and discussion, Energy Conversion and Management 114 (2016) 364-375. doi:10.1016/j.enconman.2016.02.042.

[25] R. Payri, G. Bracho, P. Marti-Aldaravi, A. Viera, Near field visualization of diesel spray for different nozzle inclination angles in non-vaporizing conditions., Atomization and Sprays 27 (2017) 1-17. doi:10. 1615/AtomizSpr.2017017949.

[26] Z.-Y. Sun, G.-X. Li, C. Chen, Y.-S. Yu, G.-X. Gao, Numerical investigation on effects of nozzle's geometric parameters on the flow and the cavitation characteristics within injector's nozzle for a highpressure common-rail DI diesel engine, Energy Conversion and Management 89 (2015) 843-861. doi 10. 1016/j.enconman.2014.10.047

[27] R. Payri, F. J. Salvador, J. Gimeno, G. Bracho, The effect of temperature and pressure on thermodynamic properties of diesel and biodiesel fuels, Fuel 90 (2011) 1172-1180. doi:10.1016/j.fuel.2010. 11.015 .

[28] R. Payri, F. J. Salvador, M. Carreres, J. De la Morena, Fuel temperature influence on the performance of a last generation common-rail diesel ballistic injector. Part II: 1D model development, validation and analysis, Energy Conversion and Management 114 (2016) 376-391. doi 10.1016/j . enconman.2016.02. 043 .

[29] R. Payri, J. Gimeno, J. Cuisano, J. Arco, Hydraulic characterization of diesel engine single-hole injec- 
Raul Payri, Jaime Gimeno, Carmen Mata, Alberto Viera; Rate of injection measurements of a direct-acting piezoelectric injector for different operating temperatures. Energy Conversion and Management, 2017, 154, 387-393. REFERENCES

tors, Fuel 180 (2016) 357-366. doi 10.1016/j.fuel.2016.03.083

[30] A. L. Kastengren, F. Z. Tilocco, C. F. Powell, J. Manin, L. M. Pickett, R. Payri, T. Bazyn, Engine Combustion Network (ECN): Measurements of Nozzle Geometry and Hydraulic Behavior, Atomization and Sprays 22 (2012) 1011-1052. doi 10.1615/AtomizSpr.2013006309.

[31] M. Bardi, Partial needle lift and injection rate shape effect on the formation and combustion of the Diesel spray, Ph.D. thesis, Universitat Politècnica de València, Valencia (Spain), 2014. doi:10.4995/ Thesis/10251/37374. 